and symposia, as well as direct research and artistic collaboration. CES is particularly committed to supporting research that can play a critical role in understanding and applying the lessons of European history and integration to contemporary problems, including those in the areas of global security, sustainability, environmental stewardship, and democracy.

Since 1979, CES has hosted the International Conference of Europeanists, the world's largest and most prestigious professional gathering for academics, researchers, and policy specialists focusing on Europe, with more than a thousand scholars attending. The Conference is held each year and alternates location between Europe and North America.

EuropeNow can be found at www.europenowjournal.org, and the editors can be contacted at editors@europenowjournal.org.

\section{New Organized Section on American Political Thought}

APSA is proud to introduce its newest organized section, Section 47: American Political Thought.

The purpose of this section is to facilitate and encourage a uniquely integrative approach to the study of politics that will put scholars of American politics, political theory, American political development, American history, philosophy, American literature, and other related fields in ongoing and fruitful conversation with one another.

Member benefit also includes subscription to American Political Thought: A Journal of Ideas, Institutions, and Culture.

\title{
STAFF SPOTLIGHT
}

\section{Steven M. Eson, Coordinator of Member Services}

Steven Eson is the Coordinator of Member Services. Steven works closely with the membership team to aid in membership recruitment, growth, retention, and superior member service. Prior to joining APSA in 2014, he obtained a Bachelor of Fine Art at the Corcoran College of Art and Design in 2008, with a focus in digital art and design. Since then, he continues freelance work as an artist, designer and writer in the Washington, DC area, and he has used his creative acumen on various projects at the association, including designing the cover of the recent APSA taskforce report, The Double Bind: The Politics of Racial and Class Inequalities in the Americas. The task force can be found here: http://www.apsanet.

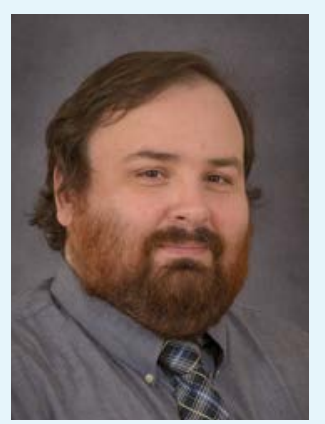
org/inequalities.

\section{Small Research Grants: Call for Applications}

APSA is now accepting applications for small research grants of up to $\$ 2,500$ to support research in all fields of political science. Applications are welcome form APSA members who are not employed at $\mathrm{PhD}$-granting departments or who are in nontenure track positions. Funds may be used for a variety of research activities, such as travel to archives, travel to conduct interviews, administration and coding of instruments, research assistance, and purchase of datasets. Note that certain activities are excluded from funding; these include travel to professional meetings, secretarial costs except for preparation of the final manuscripts for publication, and salary support for the principal investigator. Overhead or indirect costs are also not allowable expenses. Funds must be spent by September 30 of the year following the award. The deadline for applications is Saturday, April 1, 2017. For more information, contact researchgrants@ apsanet.org or visit http://www.apsanet.org/smallresearchgrant.

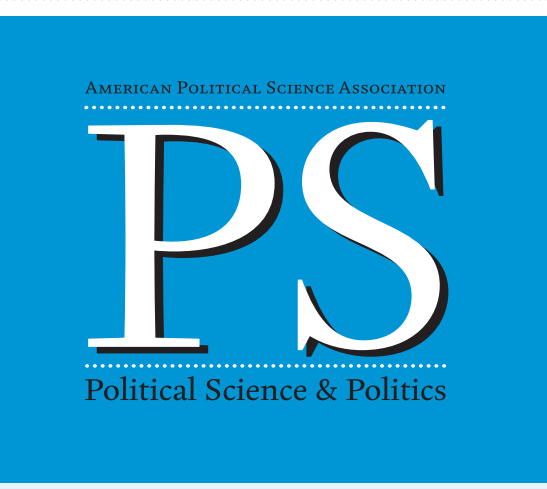

\section{In the Next Issue...}

PROFESSION SYMPOSIA

Higher Education in the Knowledge Economy: Politics and Policies of Transformation Tobias Schulze-Cleven, guest editor

Daniel Patrick Moynihan's America: The Legacies of a Professor-Politician Patrick Andelic, Louisa Hotson, and Daniel Rowe, guest editors

\section{TEACHER SYMPOSIUM}

Disembodied Shades: Teaching the Territories of the United States

Bartholomew Sparrow, guest editor

\section{ARTICLES}

Presidents, Baseball, and Wins above Expectations: What Can Sabermetrics Tell Us about Presidential Success Manuel P. Teodoro and Jon R. Bond

Gender in the Journals: Publication Patterns in Political Science

Dawn Langan Teele and Kathleen Thelen

Negating the Gender Citation Advantage in Political Science Amy L. Atchison

Gender Bias in International Relations Graudate Education? New Evidence from Syllabi Jeff Colgan

Engaging Women: Addressing the Gender Gap in Women's Networking and Productivity Tiffany D. Barnes and Emily Beaulieu 


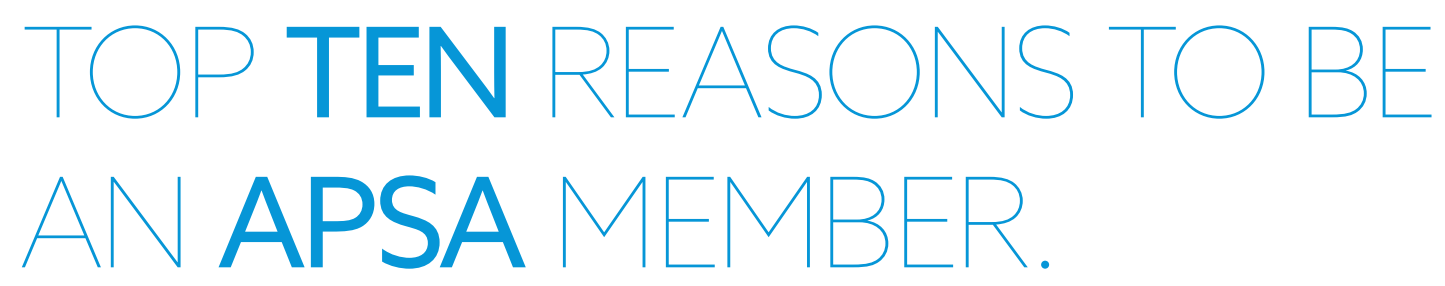

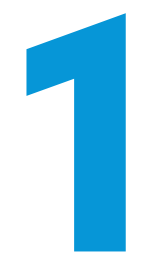

Increase your professional visibility

\& stay connected to 12,000

political science professionals.

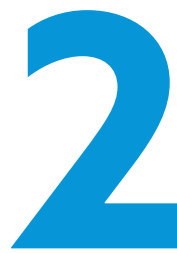

Stay up-to-date on the latest research in political science with access to APSA's three leading peer-reviewed political science journals.

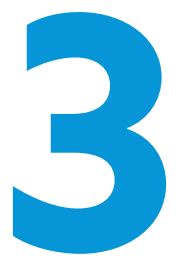

Search the latest job openings using APSA eJobs, the most comprehensive database of jobs related to political science. Browse the newest listings and upload your resume today!

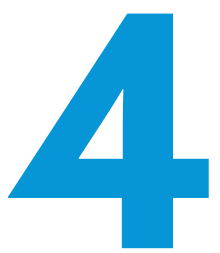

Engage with your colleagues interested in similar subfields of political science by joining an APSA Organized Section.

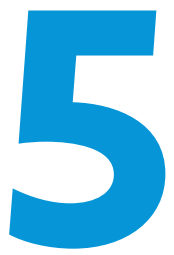

Enjoy member-only discounts of up to $46 \%$ off the registration fee for the APSA Annual Meeting and APSA Teaching \& Learning Conference.

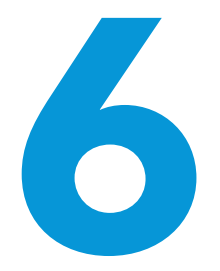

Get professional development advice \& support from experienced \& senior members of the profession through the APSA Mentoring Program.

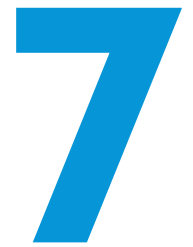

Get your research funded through one of the APSA Centennial Center's programs or by applying for a small research grant!

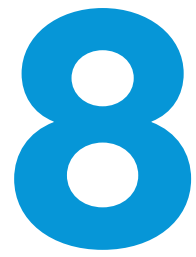

APSA recognizes excellence in the profession by awarding members for outstanding dissertations, papers, articles, \& books in various subfields of the discipline.

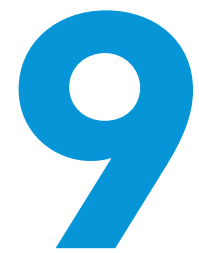

Apply for the Congressional Fellowship Program, a unique \& highly-selective non-partisan program devoted to expanding knowledge \& awareness of Congress.

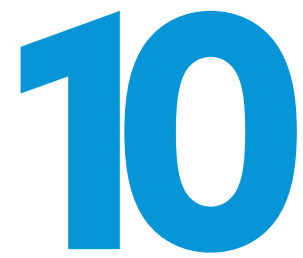

Get involved in one of APSA's International Programs designed to promote closer interaction between American and non-American political scientists. 


\section{apsa

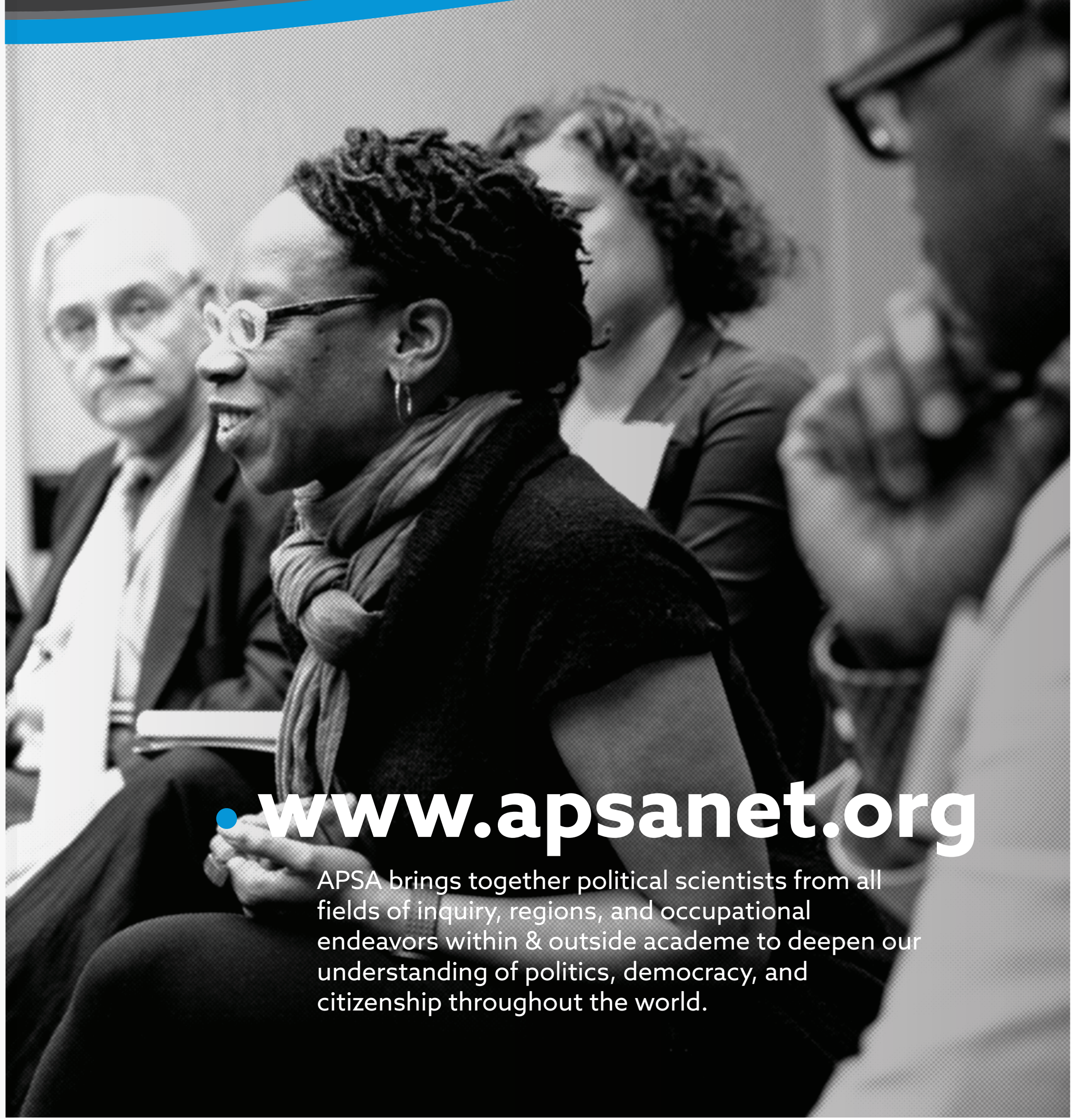

